\title{
Research and application of reliability-based cost optimization method for constant interval preventive maintenance
}

\author{
Tao Zhang*, Chen Qing, and $\mathrm{Na} \mathrm{Yu}$ \\ Suzhou Nuclear Power Research Institute, Shenzhen, China
}

\begin{abstract}
Preventive maintenance is a means to ensure the component is kept in the desired state. Lack of preventive maintenance will cause unexpected consequences for the component, and too much preventive maintenance will result in unnecessary investment of resources. Based on the reliability data of the component, this paper establishes an analysis model to determine the optimal preventive maintenance interval of the component to make the cost of preventive and corrective maintenance lowest.
\end{abstract}

Keywords: Preventive maintenance, Interval, Reliability, Cost.

\section{Introduction}

The component may degrade or fail during the operation due to operating factors or its own material characteristics. Because of different designs, the consequences of component failures are also different, some may cause safety or significant economic losses, and some may have no special impact due to redundant design. In order to prevent the component from causing unexpected failures and losses, preventive maintenance is generally adopted. Preventive maintenance is to reduce the probability of failure or functional degradation, carried out at predetermined intervals or according to prescribed criteria ${ }^{[1]}$. The probability can generally be expressed by the failure rate of the component. The predetermined interval generally refers to the preventive maintenance of constant periods. The established criteria generally include status parameters and other types of preventive maintenance except for the constant interval.

Constant interval preventive maintenance refers to do preventive maintenance of the component at a fixed time, and replacement will be carried out if the component fails during the working period. In engineering practice, it is often applied to the group replacement of component, which is suitable for parts with lower prices, smaller deviations in life distribution, and larger quantities. The core problem in constant interval preventive maintenance is to find the optimal solution of the interval. Generally include solution models targeting risk, cost, availability ${ }^{[2]}$. The main purpose of the risk solution model is to find the optimal solution so that the failure rate of the equipment is not higher than the set value, and the main purpose of the cost solution model is to find the optimal solution. to minimize the cost, the main purpose of the availability model is to find the optimal solution to maximize 
the availability. This paper is based on the cost model to study the method, which can be used to solve the preventive maintenance interval of the situation where the consequences of the failure will cause economic impact.

\section{Technical method}

\subsection{Cost}

The costs incurred during the operation and maintenance of the component mainly include preventive maintenance costs and corrective maintenance costs for repairing the component after failures. Preventive maintenance costs need to consider the labor and spare parts costs incurred during the preparation and execution of preventive maintenance. In addition, if preventive maintenance will cause component out of service, it is necessary to consider whether there will be production losses. Corrective maintenance costs need to consider the labor and spare parts costs incurred during the preparation and execution of corrective maintenance. In addition, if component failures will cause production losses, this part of the cost needs to be taken into consideration as corrective maintenance costs. The average cost of preventive maintenance is expressed in terms of $C_{1}$ and the average cost of corrective maintenance is expressed in terms of $C_{2}$.

If $N_{1}$ and $N_{2}$ represent the number of preventive maintenance and the number of failures that occurred under the preventive maintenance interval $\mathrm{T}$, then the total cost is $C_{1} N_{1}+C_{2} N_{2}$

\subsection{Failure rate}

There are many types of failure rate functions of component, the two-parameter Weibull distribution is widely used among them, which is generally used to describe the failure rate of mechanical and electronic products. The failure rate of the two-parameter Weibull distribution is expressed as follows ${ }^{[3]}$ :

$$
\lambda(t)=\beta{\frac{t}{\eta^{\beta}}}^{\beta-1}
$$

Among them $\beta$ is the shape parameter and $\eta$ is the scale parameter. The parameters can be obtained through mathematical statistics of component failure data, and can also be obtained by querying industry common data sources.

Under the two-parameter Weibull distribution, the reliability function of the component $R(t)$, the failure function of the component $F(t)$ are expressed as follows:

$$
\begin{aligned}
& R(t)=e^{-\left(\frac{t}{\eta}\right)^{\beta}} \\
& F(t)=1-e^{-\left(\frac{t}{\eta}\right)^{\beta}}
\end{aligned}
$$

The bathtub curve shown as figure 1 is often introduced when studying the failure rate of the equipment, . The first part of the curve is the infant failure period indicates the gradual decrease of the failure rate, the middle part is the random failure period, that is, the failure rate of the equipment is constant, and the latter part is the wear-out period indicates the the failure rate gradually increases. According to GB/T 34987-2017, the three stages of the curve correspond to shape parameters less than 1, equal to 1 , greater than 1 if represented by Weibull,. Some components may be in an infant or random failure period for a long time, and preventive maintenance does not improve its failure rate and therefore does not require preventive maintenance, but potential degradation detection techniques can generally be 
considered based on P-F theory to detect or predict failures in advance ${ }^{[4]}$. For wear-out failure period, preventive maintenance is particularly important to reduce the failure rate, which is also the case of this paper.

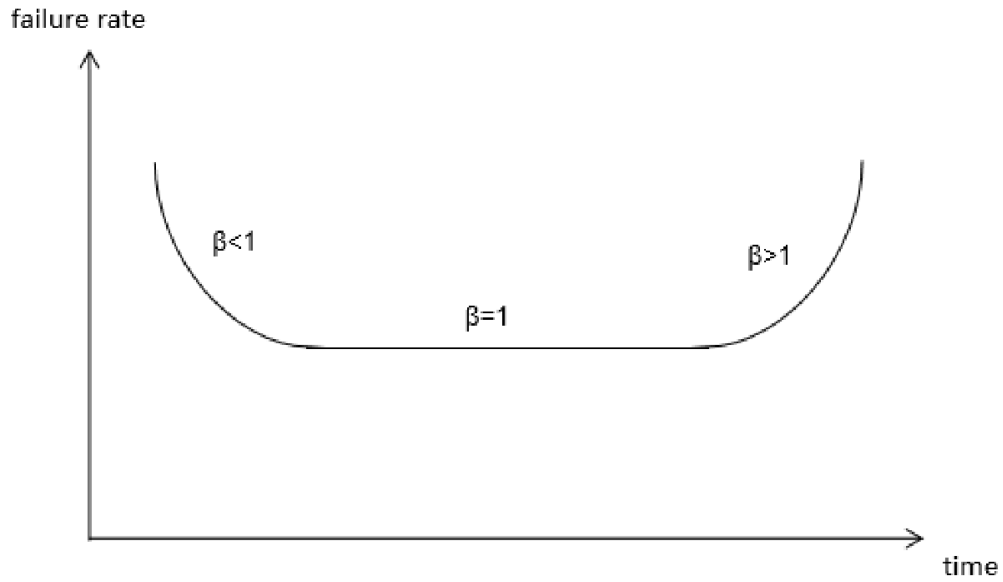

Fig. 1. Bathtub curve.

\subsection{Analysis model}

In a preventive maintenance cycle, the component may not fail, or it may fail. When a failure occurs, a corrective maintenance is performed, and then the next preventive maintenance cycle starts. Therefore, the operating time of component in each preventive maintenance cycle is not fixed, so it is necessary to introduce an expected value of component operating time in a maintenance cycle:

$$
T_{w}=\int_{0}^{T} t d F(t)+\int_{T}^{\infty} T d F(t)=\int_{0}^{T} R(t) d t
$$

Generally, there will be a longest service time due to the overall design, that is, the mission time $\mathrm{T}_{\mathrm{m}}$. For example, some factories are designed to be decommissioned after 40 years, and 40 years is the longest mission time for all component in the factory. When the mission time is limited, the total number of repairs required for the component is:

$$
\mathrm{N}=\frac{\mathrm{T}_{\mathrm{m}}}{\mathrm{T}_{\mathrm{w}}}-1=\frac{\mathrm{T}_{\mathrm{m}}}{\int_{0}^{\mathrm{T}} \mathrm{R}(\mathrm{t}) \mathrm{dt}}-1
$$

All maintenance includes preventive maintenance and corrective maintenance. The expected values of the number of preventive maintenance $\mathrm{N}_{1}$ and corrective maintenance $\mathrm{N}_{2}$ are:

$$
\begin{gathered}
\mathrm{N}_{1}=\mathrm{N} \times \frac{\mathrm{R}(\mathrm{T})}{\mathrm{R}(\mathrm{T})+\mathrm{F}(\mathrm{T})}=\mathrm{R}(\mathrm{T}) \cdot \mathrm{N} \\
\mathrm{N}_{2}=\mathrm{N} \times \frac{\mathrm{F}(\mathrm{T})}{\mathrm{R}(\mathrm{T})+\mathrm{F}(\mathrm{T})}=\mathrm{F}(\mathrm{T}) \cdot \mathrm{N}
\end{gathered}
$$

Therefore, the expected value of the total maintenance cost of the component during the mission time is:

$$
\mathrm{C}=\mathrm{C}_{1} \cdot \mathrm{N}_{1}+\mathrm{C}_{2} \cdot \mathrm{N}_{2}=\left[\frac{\mathrm{T}_{\mathrm{m}}}{\int_{0}^{\mathrm{T}} \mathrm{R}(\mathrm{t}) \mathrm{dt}}-1\right] \cdot\left[\left(\mathrm{C}_{2}-\mathrm{C}_{1}\right) \cdot \mathrm{F}(\mathrm{T})+\mathrm{C}_{1}\right]
$$

Taking the derivative of (8) and making it constant to 0 , we can get:

$$
\mathrm{T}_{\mathrm{m}} \lambda(\mathrm{T}) \int_{0}^{\mathrm{T}} \mathrm{R}(\mathrm{t}) \mathrm{dt}-\mathrm{T}_{\mathrm{m}} \mathrm{F}(\mathrm{T})-\lambda(\mathrm{T})\left[\int_{0}^{\mathrm{T}} \mathrm{R}(\mathrm{t}) \mathrm{dt}\right]^{2}=\frac{\mathrm{c}_{1} \mathrm{~T}_{\mathrm{m}}}{\mathrm{C}_{2}-\mathrm{C}_{1}}
$$

Solving equation (9), the optimal preventive maintenance cycle can be obtained. It should be noted that preventive maintenance is not required if the average cost of preventive 
maintenance is greater than the average cost of corrective maintenance, or the shape parameter is not greater than 1 .

\section{Case studies}

A valve is designed on a certain production line to adjust the flow of the fluid. During operation, there is a failure mode that jams and leads to poor adjustment. In order to prevent this failure mode, a regular preventive maintenance method of online lubrication is carried out. The production line is designed to be used for 10 years.

Through the analysis of field failure data, the failure rate distribution parameters can be obtained. After the valve fails, the production line will be suspended. The production loss and maintenance cost will be $\$ 50,000$ in total during the period from the overall replacement of the valve to the restoration of the production line. The execution of preventive lubrication will not affect the normal operation of the production line, and the total cost is $\$ 1,000$ considering the labor cost and spare parts. Its various parameters are shown in Table 1.

Table 1. Parameter value table.

\begin{tabular}{c|l|l}
\hline Parameter & Parameter description & Parameter value \\
\hline $\mathrm{T}_{\mathrm{m}}$ & Mission time & $87,600 \mathrm{hrs}$ \\
\hline $\mathrm{C}_{1}$ & $\begin{array}{l}\text { The cost of a preventive } \\
\text { maintenance every time }\end{array}$ & $\$ 1,000$ \\
\hline $\mathrm{C}_{2}$ & $\begin{array}{l}\text { The cost of a corrective } \\
\text { maintenance every time }\end{array}$ & $\$ 50,000$ \\
\hline$\beta$ & Shape parameter & 2 \\
\hline$\eta$ & Scale parameter & $39,036 \mathrm{hrs}$ \\
\hline
\end{tabular}

Substituting the parameters into equation (9), the solution is $5278 \mathrm{hrs}$, that is, the best preventive maintenance interval is $5278 \mathrm{hrs}$.

\section{Summary}

This paper establishes a model for preventive maintenance of component, takes the failure rate and the cost of various activities as input, and solves the preventive maintenance interval in the case of limited mission time and replacement after failure, so that the overall cost of preventive maintenance and corrective maintenance is the lowest. The failure rate distribution in this paper adopts the two-parameter Weibull distribution. For other special distribution types, the method in this paper can also be used for modeling and analysis. However, it should be pointed out that this paper considers that preventive maintenance can make component repaired as new, and does not consider component damage caused by improper maintenance techniques during the maintenance process.

\section{References}

1. GB/T 2900.13-2008, Electrotechnical terminology-Dependability and quality of service

2. Jia Xisheng, The Decision Models for Reliability Centered Maintenance (National Defense Industry Press)

3. GB/T 34987-2017, Weibull analysis

4. SAE JA1012-2002, A Guide to the Reliability-Centered Maintenance (RCM) Standard 